\title{
Implementation of autonomy phase during the Anaesthesia and Critical Care residency: Monocentric University Hospital experience
}

\section{Claire Dehaen-Rougelin}

Centre Hospitalier Universitaire de Rouen

alexandre grognu

Centre Hospitalier Universitaire de Rouen

Emmanuel Besnier

Centre Hospitalier Universitaire de Rouen

Thomas clavier

Centre Hospitalier Universitaire de Rouen

Benoit Veber

Centre Hospitalier Universitaire de Rouen

Bertrand dureuil

Centre Hospitalier Universitaire de Rouen

Vincent Compere ( $\boldsymbol{\nabla}$ Vincent.Compere@chu-rouen.fr )

Universite de Rouen https://orcid.org/0000-0001-5977-7090

Research article

Keywords: Supervised autonomy, Residency, Anesthesia and Critical Care

Posted Date: December 20th, 2019

DOI: https://doi.org/10.21203/rs.2.19471/v1

License: (c) (i) This work is licensed under a Creative Commons Attribution 4.0 International License. Read Full License 


\section{Abstract}

Background: A new French curriculum about anaesthesiology and critical care residency has started in November 2017 involving an autonomy phase supervised by seniors with main objective to prepare for the professional exercise. Since 10 years, Anaesthesia and Critical Care Department of Rouen University Hospital has established a similar process with autonomy practice supervised by senior doctor during the last year of residency. Our $5^{\text {th }}$ year training local program is therefore very closed from the new French anaesthesiology and intensive care residency curriculum. In our hospital, In order to project this supervised autonomy phase, the aim of this study was to assess the opinion of our former residents who benefited from our supervised autonomy phase during their last year of training.

Methods: A standardized questionnaire was sent to all the residents trained in Rouen between 2004 and 2016 and who have been involved in supervised autonomy phase. Three areas were studied: the profile of responders, the practical and theoretical training received and the supervised autonomy phase.

Results: The response rate was $84.1 \%(95 / 113)$. Theoretical and practical training was rated good or excellent for $93.7 \%$ of responders. The supervised autonomy status was noted to be positive by $94.2 \%$ of the respondents. The highlighted skills were autonomy, learning the organization of working time and preanaesthesia clinic. A majority (85\%) of the residents reported having had little or no difficulty and $97 \%$ said that this status facilitated their position as a senior physician. This phase of autonomy should be included systematically in the residency for $93 \%$ of them.

Conclusions: Supervised autonomy status would enable empowerment under secured supervision conditions. The majority of residents felt that this supervised autonomy phase should be systematically included in our training as proposed now by the new French curriculum.

\section{Background}

A new French curriculum about anaesthesiology and intensive care residency has started in November 2017. As before, the training program includes a rotation-based program, for 5 years, including stages in the operating room to perform anaesthesiology in a variety of surgical specialties and in intensive care units. The medical residency education reform introduces different levels into the training course by adapting teaching and clinical practice to the advance in curriculum. The first (1 year) and second phases (3 years) correspond in a " base » and " enhancement " phases respectively. This training is very close to previous residency course. The main novelty refers to the characterization of the last year of residency as an autonomy phase supervised (called junior doctor) by senior doctors with main objective to prepare resident for the professional practice.

This last phase of training raises several concerns from the residents and the senior doctors. Different studies have focused on the choice of the practice of anaesthesia and critical care by residents. ${ }^{1,2}$ The attractiveness of this medical speciality is due to its dynamism and the quality of the training and especially the close supervision during residency. ${ }^{3,4}$ As reported by Gautier et al., $96 \%$ of the anaesthesia 
and critical care residents were satisfied with their choice. ${ }^{5}$ Theoretical education and clinical teaching are considered as excellent in $67 \%$ of the cases or good in $89 \%$ of the cases. ${ }^{6}$ The key issue at the new curriculum is to ensure safe and excellence training especially during this last phase of residency.

Since 10 years, Anaesthesia and Critical Care Department of Rouen University Hospital has established a process with autonomy practice supervised by senior doctor during the end of residency. Our end training local program is therefore very closed from the new French anaesthesiology and intensive care residency curriculum. The aim of this study was to assess the opinion of our former residents who benefited from our supervised autonomy phase at the end of the curriculum.

\section{Methods}

Resident selection

This monocentric opinion survey was conducted at the Rouen University Hospital. All anaesthesia and critical care residents trained at the Rouen University Hospital that graduated between 2004 and 2016 and have been involved in supervised autonomy phase were included. The Ethics and Evaluation Committee for Non-Interventional Research of Rouen University Hospital approved the study ( ${ }^{\circ} 2012-$ 300). The requirement for written informed consent was waived by the Committee.

\section{Study Design}

A standardized questionnaire was sent by e-mail. The e-mail addresses were found in the archives of the Rouen University Hospital department of Anaesthesia and Intensive Care and on the other hands in the Council of Physicians to which every physician has to register as a legal obligation. Two successive reminders were sent. The questionnaires were sent electronically using a Google Forms template and the data were processed via an Excel page created by the Google server.

People were asked about 45 items divided into 4 areas: the initial profile (native region, motivation of the choice of the residency in Rouen), the current position (professional and personal), the global training (theoretical and practical) during residency and the experience about supervised autonomy phase (annexe). Different items are assessed by scale ranged from 1 to 5 .

In Rouen anaesthesiology and critical care department, supervised autonomy phase is characterized mainly by autonomy supervised by senior doctors of the overall management of the critical care and anaesthetic process. The process is described in a formalized contract. This practical training adapted to the evolution of the anaesthesia and critical care residency is made possible by the definition of a framework. The possibility of supervised autonomy phase semester is based on voluntary service from resident but also from medical team reception. It involves the coordination upstream with the medical pedagogical managers of the service and then with the medical team of reception. The work of the resident during supervised autonomy phase is always carried out under the direct responsibility of a 
senior doctor (accessible at any time, on the site and ready to help the resident). Within our department, there were two possibilities. Residents at the end of the curriculum could be involved on a voluntary base in supervised autonomy phase for day activities and/or for duty periods for anesthesia or critical care practice.

\section{Statistical analysis}

The statistical analysis was descriptive. The results were expressed in absolute value and in percentage. We did not identify any ethical problems for this study. The collected data were confidential and we chose to not request any registration on the questionnaire webpage, in order to avoid potential bias by identifying the responder.

\section{Results}

One hundred and twenty-five former residents could be included in our study. E-mail addresses could only be referenced for 113 of them. There were 95 questionnaires completed, with a response rate of $84.1 \%$.

\section{Demographics data}

The average age for responders was 36.6 years. Half of responders were married (49.5\%), $37.9 \%$ in relationship and $12.6 \%$ reported being single. One-third of the people did not have children $(34.7 \%)$. The others reported 1 child (12.6\%), 2 children for $27.4 \%$, 3 children for $20 \%$ and more than 3 children for $5.3 \%$ of the responders. Their native region was the lle-de-France for the third part (35.8\%), Haute-Normandie for $30.5 \%$, Picardie for $7,4 \%$ and the rest was distributed in all regions of France. The choice of Rouen University hospital was a geographical choice in $41.1 \%$ of the cases, the national ranking examination rank in $38.9 \%$, the reputation of the department in $12.6 \%$ of the cases and a relationship choice for the others.

In our cohort, $96.8 \%$ carried out a fellowship. The positions offered were $46.7 \%$ as clinical head, $29.3 \%$ as regional specialist assistant, $20.7 \%$ as hospital specialist assistant and $3.3 \%$ as contractual hospital practitioner.

\section{Current employment situation}

For $53.7 \%$, the clinical activity is exclusively anesthesia practice, for $16.8 \%$ exclusively critical care practice and for $29.5 \%$ mixed activity. The type and structure of exercise are university hospital for 46.4 $\%$, general hospital for $18.9 \%$, independent private hospital for $18.9 \%$, private hospital within a health group for $10.5 \%$ and private hospital non-profit health care facility for $5.3 \%$.

The number of working days per week was 5 days or more for $52.6 \%, 3$ to 4 days for $46.3 \%$ and 1 to 2 days for $1,1 \%$. A majority of people $(77.9 \%)$ had night shift activities: $41.1 \%$ reported a night shift rate of 3 to 4 per month and $32.6 \% 5$ or more per month. More than half of the respondents $(62.1 \%)$ said they had on call: $34,7 \%$ from 1 to 2 per month, $20 \%$ from 3 to 4 per month and 7,4\%, 5 or more per month. 
For the remuneration, 93 people $(97,8 \%)$ have answered. It ranges from less 2500 euros to more than 7500 euros without fee: $3,2 \%$ less than $2500 €$ per month, $42.1 \%$ earned between 2500 and $5000 €$ per month, $22.1 \%$ between 5000 and $7500 €$ per month and $30.5 \%$ more than $7500 €$ per month.

The overall satisfaction and level of difficulty felt scores of the current practice are depicted in Table 1.

Evaluation of the training during the residency at Rouen University Hospital

The majority (93.7\%) of people felt that both theoretical and practical training was good or excellent (Table 1).

The majority (98.9\%) was satisfied or very satisfied about the working conditions during the residency in Rouen. The whole population would recommend the Rouen residency formation to a friend.

\section{Supervised autonomy_phase}

In our population, $89.5 \%$ reported having been in a supervised autonomy phase during day activity and $91.6 \%$ on-call activity (37.6\% during their 8 th semester, $55.3 \%$ during their 9 th semester and $56.5 \%$ during their 10th semester)

\section{Day activity}

The areas of aesthetic and intensive care activity where residents were in supervised autonomy practice have been summarized in table 2 with a majority in Rouen University Hospital. The vast majority of respondents (82.4\%) consider that the objectives of the supervised autonomy phase were clearly defined by the department and by the medical team. Moreover, $83.5 \%$ did not encounter any difficulties or minimal difficulties during their internship. Only, $15.3 \%$ faced moderate difficulties and $1.2 \%$ significant difficulties. Situations responsible for these difficulties are depicted in table 3.

\section{On-call activity}

The on-call activity was reported for $80.2 \%$ to be performed in intensive care units and $56.3 \%$ as anesthetic in operating room. The distribution by location was summarized in Tables 4 and 5 . The difficulties encountered by the residents $(57.9 \%$ answered) during on-call activity were described in Table 6.

\section{The autonomy supervised status}

This phase was reported as beneficial for their professional formation by $94.2 \%$ of the responders. All of them found that the autonomy supervised status was associated with new fields of formation when compared with initial stages of the courses (autonomy for $94 \%$, Organization of working time for $56.6 \%$; training in anesthesia consultation for $36,1 \%$ ) 
Moreover, $72.9 \%$ of residents during supervised autonomy stage reported that they had enough free time to work for thesis or university report. Moreover, $93 \%$ thought it would be advisable to include systematically the supervised autonomy stage in anesthesia and critical care residency and $97 \%$ think that this step had made taking their position as anesthesiologist-intensivist seniors easer. Responders recommend this stage to a friend during day activity for $98.5 \%$ and during on-call activity for $92.4 \%$ of them.

\section{Suggestions of residents to improve the curriculum}

In addition, they suggested that 2 important skills must be improved during residency: the anesthetic consultation and the post-operative care of the patients. Moreover, people would have a facilitated access to university diplomas. University diplomas such as cardiac ultrasound, pediatric anesthesia, regional anesthesia were strongly suggested.

\section{Discussion}

This survey highlights the supervised autonomy stage during anesthesia and critical care residency. More of $90 \%$ of people experimented day and/or on-call supervised autonomy stage at the end of residency with positive effect for their subsequent professional activity in $95 \%$ of case. The main difficulties were related to medical reasoning, relationship with surgical team, organization of operating theatre and stress related with autonomy.

There were some limitations to our study. The response rate was high $84 \%$ but with potential selection bias even if it seemed in accordance with other works. Surveys conducted with anesthesia and critical care residents had varying response rates from $40 \%$ (national survey) ${ }^{2}$ to $61 \%$ (inter-regional survey). ${ }^{1}$ There were also large variations between residents starting their residency and those completing them ( $44 \%$ for the first year versus $77 \%$ for the fourth year) ${ }^{5}$. Two other points raised us in the analysis of our population. In fact, $46 \%$ of respondents reported working in a university hospital. It seems likely that physicians working within our university structure were easier to reach and more aware of our study. Finally, our study focused only on the feelings of the residents with retrospective auto evaluation design.

Anesthesia and Critical Care remains an attractive specialty. Our work shows that the doctors have a very good view about working conditions (3\% unsatisfied or few satisfied of current practice) with only $30 \%$ of people think that it's arduousness work. Indeed, the attractiveness of anesthesia and critical care residency has dramatically increased during last years. In $2008,80 \%$ of the medical students chose this specialty in first intention in comparison with $47 \%$ in $2002 .{ }^{2,5}$ Only very small number of residents is not satisfied about their orientation at the end of their residency. ${ }^{2,6}$ The attractive conditions involve several points: versatility, access to different areas of activity between anesthesia and critical care residency associated with a high level of training and supervision by senior doctor. In our study, theoretical and practical training in our university was rated as good or excellent for $93.7 \%$ of respondents. The satisfaction of residents has stable since 2011. It was already over $90 \%$ in a survey carried out in the 
France northern region. ${ }^{1}$ People stated that the training during residency allows the successful transition to independent practice. The majority (98.9\%) was satisfied or very satisfied about the working conditions during the residency in Rouen.

The main novelty of residency reform refers to the characterization of the last year of residency by autonomy phase supervised by seniors in order to prepare for the professional exercise. In our department, this status has been developed since 2004 . A majority of residents (90\%) had experimented this status in our institution. This position has been considered as beneficial by $95 \%$ of our residents. The totally of people noted a difference in comparison with the rest of their residency. More than $80 \%$ consider that the objectives of the supervised autonomy phase were clearly defined by the department of anesthesia-critical care and by the medical team of reception. In congress abstract, a similar experience of supervised autonomy phase was carried out in the lle de France region in $2013 .{ }^{7}$ The aim of this study was the identification of potentially dangerous situations and the evaluation of the experience by the resident of these situations. A checklist containing 16 items had been developed. It evaluated the adequacy of the pre-, per- and post-operative anesthesia strategy previously established at a weekly meeting with the senior doctors of the team. The resident also filled out self-assessment and satisfaction forms. The management had been judged to be in line with expectations by the residents and seniors. Non-opposition has been observed by the medical-surgical team. This study is in accordance with our results with a high satisfaction of this status by residents.

The main role of a residency is to train student physicians who can practice medicine independently and safely. In the study of Franzone et al. regarding residents of surgery, the current system of graduated responsibility and progressive independence appears to fall short of this goal for a large portion of learners. ${ }^{8}$ The residents do not feel adequately prepared to practice independently and that a significant percentage of physicians in practice believe that residency graduates are not ready to begin safety independent practice. The ideal system of graduated responsibility would include a well-structured curriculum focused on stepwise learning, complemented by robust faculty development and active mentorship. The critics who were mentioned by the residents in this study were: too much responsibility early in residency and too later in training, a lack of feedback on their skills levels and a lack of teacher training on how to appropriate the independence. The study of Hashimoto et al. seems in accordance with these conclusions. ${ }^{9}$ The progressive autonomy of the residents is a crucial step in ensuring a safe transition to an independent practice of young graduate doctors. "See more, do more and teach more" would provide the best care to patients. A meta-analysis about resident supervision in the operating room demonstrated either a positive or neutral effect on patient specific outcomes of all types (complications, mortality, operating room time, pain) when trainees were directly or indirectly supervised by attending providers. ${ }^{10}$

Furthermore, Hauer et al. tried to discriminate how supervisors develop and experience trust in the resident. ${ }^{11}$ Supervisors commonly characterized the meaning of trust based on the time spent in checking resident work. The success of a supervisory relationship is possible if the senior physician takes 
on the role of a coach or a mentor. Supervisors perceived that their trust in the residents could be enabled for them to participate more independently in the patient care. Finally, it seems to have a real impact in the training of residents at the end of the residency to implement this phase of progressive autonomy. The highlighted skills were autonomy, learning the organization of working time and anesthetic consultation. These benefits allow the successful transition to independent practice. The arduousness of this status has not been emphasized. The objectives were clearly defined by the supervisors. Moreover, $15 \%$ had difficulties during this stage. Residents experienced stress related to their new status for $47 \%$ of them on on-call activities and $35 \%$ on day activities. The other reasons were mainly relational or organizational difficulties. These aspects were inaccessible during junior status. Some aspects of the supervision of the residents can still be improved and must lead to the development of an optimized system of progressive autonomy.

\section{Conclusion}

In conclusion, our study shows that supervised autonomy status would enable empowerment under secured supervision conditions. The majority of residents felt that this supervised autonomy phase should be systematically included in our training. A new French curriculum about anaesthesiology and intensive care residency will begin in November 2017 adds this last year of residency with autonomy phase supervised by seniors in order to prepare for the professional exercise.

\section{Declarations}

\section{Availability of data and materials}

All data and materials are available upon direct request to the authors.

\section{Funding}

The authors have disclosed that they hold no financial interests related to the conduct or results of this research.

Acknowledgements: not applicable

\section{Author Information}

Department of Anaesthesia and Intensive Care, Rouen University Hospital, Rouen, France.

Claire Dehaen-Rougelin, Alexandre Grognu, Emmanuel Besnier, T Clavier, B. Veber, B. Dureuil, V. Compère Normandie Univ, UNIROUEN, Inserm U982, Mont-Saint-Aignan, France. V. Compère

\section{Authors Contribution}


CDR helped in the study conception and design, in acquisition of data, in statistical analysis, in analysis and interpretation of data and in manuscript draft.

AG helped in the study conception and design, in acquisition of data, in analysis and interpretation of data and in manuscript draft.

EB helped in interpretation of data and manuscript revision.

TC helped in interpretation of data and manuscript revision.

BV helped in interpretation of data and manuscript revision.BV was involved in resident recruitment and in manuscript revision.

BD helped in interpretation of data and manuscript revision.

VC helped in the study conception and design, in resident recruitment, in study coordination, in interpretation of data, and in manuscript revision.

\section{Ethics declarations}

Ethics approval and consent to participate

The Ethics and Evaluation Committee for Non-Interventional Research of Rouen University Hospital approved the study ( $\left.n^{\circ} 2012-300\right)$. The requirement for written informed consent was waived by the Committee because this study does not fall under the "Jardé Act" (2012-300 of 2012/03/05)

\section{Consent for publication}

Was obtained from all authors.

\section{Competing interests}

The authors declare that they have no competing interests.

\section{Abbreviations}

UH: Rouen University Hospital

\section{References}

1. Monthé-Sagan K, Leclerc C, Hanouz J-L, Fellahi J-L. Comment les anesthésistes-réanimateurs français apprennent-ils leur spécialité? Une enquête de ressenti auprès des internes de l'inter-région Nord. Annales Françaises d'Anesthésie et de Réanimation 2013;32:397-401.

2. Perbet S, Eisenmann N, Constantin J-M, Colomb S, Soummer A, Jaber S, Bazin J-E. Évaluation des motivations de choix et de leur cursus d'apprentissage par les internes d'anesthésie-réanimation: 
enquête nationale. Annales Françaises d'Anesthésie et de Réanimation 2010;29:93-103.

3. Emmanouil B, Goldacre MJ, Lambert TW. Aspirations to become an anaesthetist: longitudinal study of historical trends and trajectories of UK-qualified doctors' early career choices and of factors that have influenced their choices. BMC Anesthesiology 2017;17. Available at:

http://bmcanesthesiol.biomedcentral.com/articles/10.1186/s12871-017-0392-5. Accessed November 6, 2019.

4. Roberts LJ, Khursandi DCS. Career Choice Influences in Australian Anaesthetists. Anaesthesia and Intensive Care 2002;30:355-9.

5. Gautier J-F, N'Guyen J-L, Soltner C, Beydon L. Les internes en anesthésie-réanimation - une enquête nationale. Annales Françaises d'Anesthésie et de Réanimation 2004;23:794-8.

6. Dureuil B. II n'y a pas en France de crise des vocations en anesthésie-réanimation. Annales Françaises d'Anesthésie et de Réanimation 2004;23:779-80.

7. Suria, S, Eghiaian, A, Bourgain JL. Mise en sécurité du processus d'autonomisation des internes d'anesthésie en fin de cursus. 2013;32.

8. Franzone JM, Kennedy BC, Merritt H, Casey JT, Austin MC, Daskivich TJ. Progressive Independence in Clinical Training: Perspectives of a National, Multispecialty Panel of Residents and Fellows. Journal of Graduate Medical Education 2015;7:700-4.

9. Hashimoto DA, Bynum WE, Lillemoe KD, Sachdeva AK. See More, Do More, Teach More: Surgical Resident Autonomy and the Transition to Independent Practice. Academic Medicine 2016;91:75760.

10. Farnan JM, Petty LA, Georgitis E, Martin S, Chiu E, Prochaska M, Arora VM. A Systematic Review: The Effect of Clinical Supervision on Patient and Residency Education Outcomes. Academic Medicine 2012;87:428-42.

11. Hauer KE, Oza SK, Kogan JR, Stankiewicz CA, Stenfors-Hayes T, Cate O ten, Batt J, O'Sullivan PS. How clinical supervisors develop trust in their trainees: a qualitative study. Medical Education 2015;49:783-95.

\section{Tables}

Table 1

\begin{tabular}{|c|c|c|c|c|c|}
\hline & 1 & 2 & & 4 & 5 \\
\hline Satisfaction of the current practice & 1.1 & 2.1 & 24.2 & 52.6 & 20 \\
\hline Score level of difficulties felt for current practice & 7.4 & 25.3 & 44.1 & 21.1 & 2.1 \\
\hline $\begin{array}{l}\text { Satisfaction score regarding of the theorical training in } \\
\text { anesthesiology and intensive care at Rouen University } \\
\text { Hospital }\end{array}$ & 0 & 2.1 & 3.2 & 52.6 & 42.1 \\
\hline Satisfaction of the practical training & 1.1 & 1.1 & 4.2 & 44.2 & 49.4 \\
\hline Arduousness of residency status & 28.2 & 40 & 25.9 & 5.9 & \\
\hline
\end{tabular}


Table 2

\begin{tabular}{lc}
\hline & $\mathrm{n}=85 / \%$ \\
\hline Emergency surgery (UH) & $24 / 28.2 \%$ \\
Orthopedic surgery (UH) & $23 / 27.1 \%$ \\
Urologic and digestive surgery (UH) & $19 / 22.4 \%$ \\
Vascular-thoracic surgery (UH) & $18(21.2 \%)$ \\
Neurosurgical Intensive Care (UH) & $17(20)$ \\
Day surgery (UH) & $16(18.8 \%)$ \\
General surgery (general hospital) & $14(16.5 \%)$ \\
Surgical Intensive Care Unit (UH) & $11(12.9 \%)$ \\
Cardiac surgical Intensive Care (UH) & $9(10.6 \%)$ \\
Intensive care (general hospital) & $9(10.5 \%)$ \\
Pediatric surgery (UH) & $8(9.4 \%)$ \\
ORL surgery (UH) & $7(8.2 \%)$ \\
Ophtalmology surgery (UH) & $6(7.1 \%)$ \\
Other & $4(4.7 \%)$ \\
Maternity (UH) & $3(3.5 \%)$ \\
Medical Intensive Care (UH) & $3(3.5 \%)$ \\
Maternity (general hospital) & $3(3.5 \%)$ \\
\hline
\end{tabular}

Table 3 


\begin{tabular}{lc}
\hline & $\mathrm{n}=57 / \%$ \\
\hline Organization of the operating room & $23 / 40.4 \%$ \\
Situation related to medical reasoning & $18 / 31.6 \%$ \\
Stress related to autonomy status & $20 / 35.1 \%$ \\
Relationship with surgical team & $19 / 33.3 \%$ \\
Organization of the surgical team & $14 / 24.6 \%$ \\
Relationship with paramedical team & $11 / 19.3 \%$ \\
Lack of supervision & $8 / 14 \%$ \\
Relationship with medical team & $5 / 8.8 \%$ \\
Problems related to technical acts & $2 / 3.5 \%$ \\
Relationship with others residents & $1 / 1.8 \%$ \\
\hline
\end{tabular}

Table 4

\begin{tabular}{ll}
\hline & $\mathrm{n} / \%$ \\
\hline General hospital & $19 / 42.2 \%$ \\
& $28 / 62.2 \%$ \\
Emergency surgery room (UH) & \\
Maternity (general hospital) & $6 / 13.3 \%$ \\
\hline
\end{tabular}

Table 5

$\mathrm{n} / \%$

Surgical Intensive Care Unit (UH) $\quad 11 / 16.2 \%$

Cardiac Surgical Intensive Care Unit (UH) $13 / 19.1 \%$

Neurosurgical Intensive Care Unit (UH) $\quad 38$ / 55.9 \%

Medical Intensive Care Unit (UH) $\quad 3 / 4.4 \%$

Intensive Care Unit (general hospital) $\quad 23 / 33.8 \%$

Other

$3 / 4.4 \%$ 
$\mathrm{n} / \%$

Situation related to medical reasoning

$22 / 40 \%$

Problems related to technical acts

$2 / 3.6 \%$

Lack of supervision

$1 / 1.8 \%$

Relationship with medical team

$2 / 3.6 \%$

Relationship with co-residents

$1 / 1.8 \%$

Relationship with paramedical team

$4 / 7.3 \%$

Relationship with surgical team

$13 / 23.6 \%$

Related to the stress of autonomy status

$26 / 47.3 \%$

Related to the organization of the surgery room

$11 / 20 \%$

Related to the organization of the surgical team

$3 / 5.5 \%$

Other

$3 / 5.5 \%$

\section{Figures}

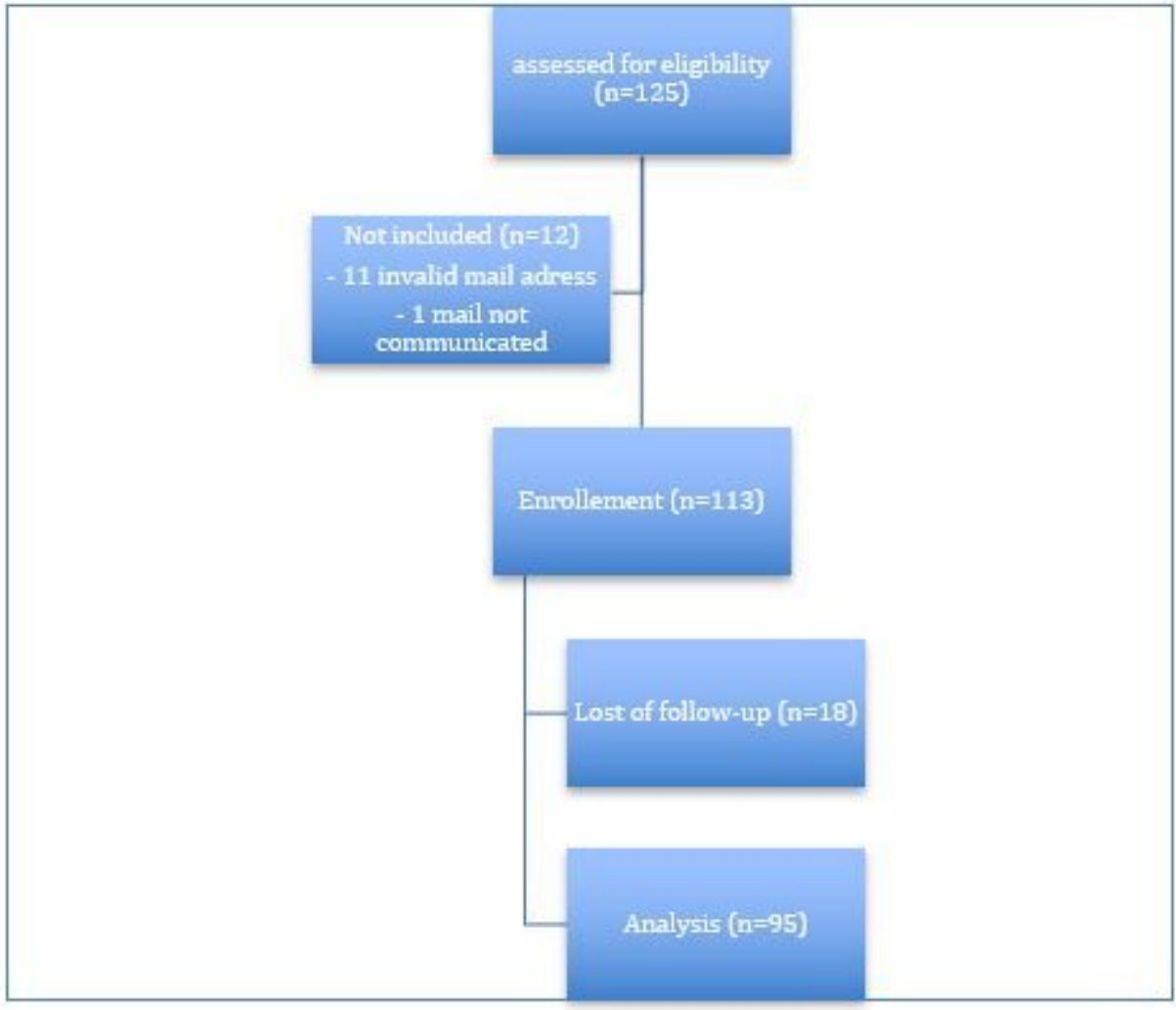

Figure 1 
Flow-chart

Page 14/14 